Original Article

\title{
ESTIMATION OF CELECOXIB IN HUMAN PLASMA BY RAPID AND SELECTIVE LC-MS/MS METHOD FOR A BIOEQUIVALENCE STUDY
}

\author{
NIRAV P. PATEL ${ }^{a, b *}$, MALLIKA SANYAL,c, PRANAV S. SHRIVASTAVd*, BHAVIN N. PATELa
}

aBio-Analytical Laboratory, Cliantha Research India Ltd., Bodakdev, Ahmedabad 380054, Gujarat, India, bKadi Sarva Viswavidyalaya Sector-15, Ghandhinagar 382715, Gujarat, India, cDepartment of Chemistry, St. Xavier's College, Navrangpura, Ahmedabad 380009, Gujarat, India, dDepartment of Chemistry, School of Sciences, Gujarat University, Navrangpura, Ahmedabad 380009, Gujarat, India Email: p.nirav_007@yahoo.com

Received: 03 Jul 2018 Revised and Accepted: 18 Aug 2018

\section{ABSTRACT}

Objective: A selective, sensitive and rapid liquid chromatography-tandem mass spectrometry (LC-MS/MS) assay has been developed for the determination of celecoxib (CXB) in negative ionization mode.

Methods: Celecoxib and celecoxib-D7 (CXB-D7) as internal standard (IS) were extracted from $300 \mu$ l human plasma by solid-phase extraction using strata-X SPE cartridges. Chromatographic separation was achieved on ACE C8-300 (50 × $4.0 \mathrm{~mm}, 3.0 \mu \mathrm{m})$ column using methanol-1.0 mmol ammonium acetate solution in 80:20 (v/v) ratio. The protonated precursor to product ion transitions studied for CXB and CXB-D7 were $\mathrm{m} / \mathrm{z} 380.0$ $\rightarrow 315.9$ and $387.0 \rightarrow 323.0$, respectively.

Results: The limit of detection (LOD) and lower limit of quantitation of the method were $2.50 \mathrm{and} 10.0 \mathrm{ng} / \mathrm{ml} \mathrm{respectively} \mathrm{with} \mathrm{a} \mathrm{linear} \mathrm{dynamic}$ range of $10.0-4000 \mathrm{ng} / \mathrm{ml}$ for CXB. The intra-batch and inter-batch precision (\% CV) and mean relative recovery across quality control levels is $<7.2$ $\%$ and $85.5 \%$ respectively. Matrix effect in human plasma, expressed as IS-normalized matrix factor ranged from 0.99-1.03.

Conclusion: The method was successfully applied in healthy subjects using a single dose of 400 mg celecoxib capsules under fasting and fed conditions. The reproducibility in the measurement of study data is demonstrated by incurred sample reanalysis.

Keywords: Celecoxib; LC-MS/MS; Solid-phase extraction; Human plasma; Bioequivalence study; Incurred sample reanalysis

(C) 2018 The Authors. Published by Innovare Academic Sciences Pvt Ltd. This is an open access article under the CC BY license (http://creativecommons.org/licenses/by/4.0/) DOI: http://dx.doi.org/10.22159/ijpps.2018v10i10.28289

\section{INTRODUCTION}

Celecoxib (CXB) is the first cyclooxygenase 2-selective inhibitor introduced into clinical practice. It is approved worldwide for the relief of the signs and symptoms of osteoarthritis, rheumatoid arthritis and ankylosing spondylitis. It is used in the management and treatment of primary dysmenorrhoea and for acute pain in adults [1]. After oral administration of $200 \mathrm{mg}$ of celecoxib to healthy volunteers the maximum plasma concentration $\left(C_{\max }, 450\right.$ $800 \mathrm{ng} / \mathrm{ml}$ ) is reached in $1.5-3 \mathrm{~h}$. The low solubility of the drug appears to prolong the absorption process making terminal half-life $\left(t_{1 / 2}\right)$ determinations more variable. Under fasted conditions, $t_{1 / 2}$ is approximately 9-11 h. Due to the low aqueous solubility of CXB, absolute bioavailability studies have not been conducted $[1,2]$.

Various methods have been reported for the determination of CXB in biological fluids. This includes liquid chromatography (LC) with spectrophotometric detection [3-7], liquid chromatography-mass spectrometry (LC-MS) [8], ultra performance LC-inductively coupled plasma mass spectrometry (UPLC-ICPMS) [9] and LC coupled with tandem mass spectrometry (LC-MS/MS) [10-12]. Several of these methods involve tedious liquid-liquid extraction (LLE) for sample preparation $[4,5,8,9,11]$. In two previous methods [6, 7], protein precipitation (PP) was employed, but the spectrophotometric detection at $254 \mathrm{~nm}$ was less selective and therefore necessitated chromatographic separation of CXB and internal standard from endogenous interferences. This resulted in longer chromatographic analysis times ( $\geq 6 \mathrm{~min}$ ). Except one report [12], all other methods have long analysis time and required extensive sample preparation.

Thus, the aim of this study was to simplify sample preparation step using solid phase extraction (SPE) and simultaneously to shorten the chromatographic run time with a more selective LC-MS/MS procedure. Further, to improve the precision and accuracy of the method isotopically labeled CXB was used compared to general internal standards employed in previously studies $[8,11,12]$. These improvements enabled development of a rapid, selective and sensitive LC-MS/MS method for determination of CXB in human plasma. The method was successfully applied to a pharmacokinetic study under fed and fasting states.

\section{MATERIALS AND METHODS}

\section{Chemicals and materials}

Reference standards of CXB (99.53\%) and celecoxib-D7 (IS, 98.42 $\%$ ) were purchased from Clearsynth Labs (P) Ltd. (Mumbai, India). HPLC grade methanol, analytical grade formic acid and ammonium acetate were obtained from SD Fine Chemicals Ltd. (Mumbai, India). Deionized water for LC-MS/MS was prepared using Milli Q water purification system from Millipore (Bangalore, India). Samples were centrifuged on Eppendorf 5810 centrifuge machine (Hamburg, Germany). Phenomenex Strata- $X^{\circledR}$ (1 cc, $30 \mathrm{mg}$ ) extraction cartridges were procured from Phenomenex (Hyderabad, India). Control buffered $\left(\mathrm{K}_{2}\right.$-EDTA) human plasma was obtained from Clinical Department, Cliantha Research India Limited (Ahmedabad, India) and was stored at $-20^{\circ} \mathrm{C}$ until use.

\section{LC-MS/MS instrumentation and conditions}

The liquid chromatography system from Shimadzu (Kyoto, Japan) consisted of a LC-10ADvp pump, an autosampler (SIL-HTc) and an on-line degasser (DGU-14A). Chromatographic analysis was performed on ACE C8-300 $(50 \times 4.0 \mathrm{~mm}, 3.0 \mu \mathrm{m})$ column from Chromatopak Analytical Instrumentation Pvt. Ltd. (Mumbai, India). The mobile phase consisting of methanol-1.0 mmol ammonium acetate in $80: 20(\mathrm{v} / \mathrm{v})$ ratio, was delivered at a flow rate of 0.5 $\mathrm{ml} / \mathrm{min}$. The auto sampler temperature was maintained at $4{ }^{\circ} \mathrm{C}$ and the injection volume was $2.0 \mu$. The total $\mathrm{LC}$ run time was $2.5 \mathrm{~min}$. Ionization and detection of CXB and IS was performed on a triple quadrupole mass spectrometer, API-4000 equipped with Turbo Ion spray ${ }^{\circledR}$, from MDS SCIEX (Toronto, Canada) and operated in the negative ionization mode. Quantitation was done using multiple 
reaction monitoring (MRM) mode to monitor protonated precursor $\rightarrow$ product ion transition of $m / z 380.0 \rightarrow 315.9$ for CXB and $387.0 \rightarrow$ 323.0 for IS. All the parameters of LC and MS were controlled by Analyst software version 1.6.2.

The source dependant mass parameters maintained for CXB and IS were Gas 1(nebulizer gas): 55 psi, Gas 2(heater gas): 60 psi, ion spray voltage (ISV):-4500 V, turbo heater temperature: $500{ }^{\circ} \mathrm{C}$, collision activation dissociation (CAD): 8 psi, curtain gas (CUR): 25 psi. The compound dependent parameters like declustering potential (DP), collision energy (CE), entrance potential (EP) and cell exit potential (CXP) were optimized at-120,-39,-10 and-10 V for CXB and-120,-35,-10 and-20 V for IS respectively. Quadrupole 1 and quadrupole 3 were maintained at unit resolution and the dwell time was set at $500 \mathrm{~ms}$.

\section{Preparation of standard stock and plasma samples}

Separate standard stock solutions $(500 \mu \mathrm{g} / \mathrm{ml})$ were prepared by dissolving requisite amount of CXB and CXB-D7 in methanol. The CXB solution was further diluted appropriately to get an intermediate concentration of $80.0 \mu \mathrm{g} / \mathrm{ml}$. The working solutions of CXB required for spiking plasma calibration and quality control samples were prepared using the standard and intermediate stock solutions in methanol: water $(90: 10, v / v)$. IS working solution of $1500 \mathrm{ng} / \mathrm{ml}$ was prepared using the stock solutions in deionized water. The calibration standards (CSs) and quality control (QC) samples (LLOQ QC, lower limit of quantitation quality control; LQC, low quality control; MQC-1 and MQC-2, medium quality control; HQC, high quality control; ULOQ QC, upper limit of quantitation quality control) were prepared by spiking blank plasma with respective working solutions. CSs were made at 10.0, 20.0, 50.0, 100, 200, 400, $800,1600,3200$ and $4000 \mathrm{ng} / \mathrm{ml}$. QCs were prepared at $10.0 \mathrm{ng} / \mathrm{ml}$ (LLOQ), $30.0 \mathrm{ng} / \mathrm{ml}$ (LQC), $300 \mathrm{ng} / \mathrm{ml}$ (MQC-2), $1200 \mathrm{ng} / \mathrm{ml}$ (MQC-1), $3000 \mathrm{ng} / \mathrm{ml}$ (HQC) and $4000 \mathrm{ng} / \mathrm{ml}$ (ULOQ) for CXB. Standard stock and working solutions used for spiking were stored at $2-8{ }^{\circ} \mathrm{C}$, while CSs and QC samples in plasma were kept at $-20^{\circ} \mathrm{C}$ until use.

\section{Protocol for sample preparation}

Prior to analysis, spiked plasma samples were thawed and allowed to equilibrate at room temperature. The samples were adequately vortexed using a vortexer before pipetting. Aliquots of $300 \mu \mathrm{l}$ plasma solutions containing $15 \mu \mathrm{l}$ of working solution of CXB and $285 \mu \mathrm{l}$ blank plasma were transferred into ria vials. Further, $15 \mu \mathrm{l}$ of methanol: deionized water $(90: 10, v / v), 100 \mu \mathrm{l}$ working solution of IS (1500 $\mathrm{ng} / \mathrm{ml}$ ) was added and vortexed to mix. To the same vials, $100 \mu \mathrm{l}$ of 2 $\%$ formic acid solution was added and vortexed again. Prior to loading plasma samples, SPE cartridges were pre-washed with $1.0 \mathrm{ml}$ of methanol, followed by $1.0 \mathrm{ml}$ of deionized water and centrifuged for $1.0 \mathrm{~min}$ at $1811 \times \mathrm{g}$. Plasma samples were then applied to these conditioned cartridges and after centrifugation for $2.0 \mathrm{~min}$ at $1811 \times \mathrm{g}$, washing was done with $1.0 \mathrm{ml}$ of deionized water, followed by centrifugation for $1.0 \mathrm{~min}$ at $1811 \times \mathrm{g}$. Elution was carried out with 2.0 $\times 250 \mu \mathrm{l}$ of methanol-1.0 mmol ammonium acetate (80:20, v/v), followed by centrifugation for $1.0 \mathrm{~min}$ at $1811 \times \mathrm{g}$ after each step and $2.0 \mu \mathrm{l}$ was used for injection in LC-MS/MS, in partial loop mode.

\section{Methodology for validation}

Method validation for CXB in human plasma was done following the USFDA guidelines [13] and the procedures followed were similar to reported methods $[14,15]$. The method was validated for selectivity, interference check, carryover, linearity, precision and accuracy, reinjection reproducibility, recovery, ion suppression/enhancement, matrix effect, stability, dilution integrity and ruggedness.

\section{Bioequivalence study design and incurred sample reanalysis (ISR)}

The design of the study comprised of "An open label, randomized, two period, two treatment, two sequence, crossover, balanced, single dose, evaluation of relative oral bioavailability of test (400 mg celecoxib capsules from an Indian company) and reference formulations (CELEBREX ${ }^{\circledR}, 400 \mathrm{mg}$ celecoxib capsules from G. D. Searle LLC, Pfizer Inc, NY, NY 10017 USA) in 50 healthy Indian male subjects under fasting and 42 healthy Indian male subjects under fed conditions. The study was carried out at Bio-Analytical Laboratory,
BA Research India Ltd., Ahmedabad, India. All the subjects were informed of the aim and risk involved in the study and a written consent were obtained. The inclusion criteria for volunteer selection was based on the age (18-45 y), body mass index (18.5-24.9 $\mathrm{kg} / \mathrm{height}^{2}$ ), general physical examination, electrocardiogram and laboratory tests like haematology, blood chemistry, urine examination and immunological tests. The exclusion criteria included allergic responses to CXB, volunteers with history of alcoholism, smokers and having a disease which may compromise the haemopoietic, gastrointestinal, renal, hepatic, cardiovascular, respiratory, central nervous system, diabetes, psychosis or any other body system. The work was approved and subject to review by Institutional Ethics Committee, an independent body comprising of eight members that included a lawyer, medical doctors, social workers, pharmacologists and academicians. The procedures followed while dealing with human subjects were based on International Conference on Harmonization, E6 Good Clinical Practice guidelines [16]. The subjects were fasted $10 \mathrm{~h}$ before administration of the drug formulation for fasted study. For fed study, the subjects were fasted $10 \mathrm{~h}$ prior to serving standardized high-calorie and high-fat breakfast. Subjects remained seated in an upright position on bed for initial $4.0 \mathrm{~h}$ post-dose and only necessary movement was allowed during this period for both the studies. Water intake was restricted $1.0 \mathrm{~h}$ before and after dosing. Blood samples were collected in vacutainers containing $\mathrm{K}_{2}$ EDTA at 0.0 (pre-dose), 0.5, 1.0, 1.5, 2.0, 2.5, 3.0, 3.5, 4.0, 4.5, 5.0, 6.0, 8.0, 10, 12 , $24,36,48$ and $72 \mathrm{~h}$ for fasting study and at 0.0 (pre-dose), 1.0, 2.0, $3.0,4.0,5.0,6.0,7.0,8.0,9.0,10,11,12,24,36,48$ and $72 \mathrm{~h}$ for fed study after oral administration of the drug. Blood samples were centrifuged at $1811 \mathrm{~g}$ at $4{ }^{\circ} \mathrm{C}$ for $15 \mathrm{~min}$; the plasma obtained was separated and stored at $-20^{\circ} \mathrm{C}$ until use.

The pharmacokinetic parameters were estimated by noncompartmental model using WinNonlin software version 5.2.1 (Certara, Princeton, NJ 08540, USA). The $C_{\max }$ values and the time to reach maximum plasma concentration $\left(T_{\max }\right)$ were estimated directly from the observed plasma concentration vs. time data. The area under the plasma concentration-time curve from time 0 to $72 \mathrm{~h}$ $\left(\mathrm{AUC}_{0-72 \mathrm{~h}}\right)$ was calculated using the linear trapezoidal rule. The $\mathrm{AUC}_{0 \text {-inf }}$ was calculated as: $\mathrm{AUC}_{0 \text {-inf }}=\mathrm{AUC}_{0-24 \mathrm{~h}}+C_{\mathrm{t}} / \mathrm{K}_{\mathrm{el}}$, where $C_{\mathrm{t}}$ is the last plasma concentration measured and $K_{\mathrm{el}}$ is the elimination rate constant; $K_{\mathrm{el}}$ was determined using linear regression analysis of the logarithm linear part of the plasma concentration-time curve. The $t_{1 / 2}$ of CXB was calculated as: $t_{1 / 2}=\ln 2 / K_{\text {el }}$. To determine whether the test and reference formulations were pharmacokinetically equivalent, $C_{\max }, \quad \mathrm{AUC}_{0-72 \mathrm{~h}}$, and $\mathrm{AUC}_{0 \text {-inf }}$ and their ratios (test/reference) using log transformed data were assessed; their means and $90 \%$ CIs were analyzed by using $\mathrm{SAS}^{\circledR}$ software version 9.1 (SAS Institute Inc., Cary, NC, USA). The drugs were considered pharmacokinetically equivalent if the difference between the compared parameters was statistically non-significant $(P \geq 0.05)$ and the $90 \%$ confidence intervals (CI) for these parameters were within $80-125 \%$.

An incurred sample re-analysis (ISR) was also conducted by computerized random selection of 316 subject samples near $C_{\max }$ and the elimination phase for this study as reported previously [17]. The results obtained were compared with the data obtained earlier for the same sample using the same procedure. As per the acceptance criterion at least two-thirds of the original and repeat results should be within $20 \%$ of each other.

\section{RESULTS AND DISCUSSION}

\section{Method development}

The objective of the present work was to develop and validate a simple, rugged, selective and sensitive method for CXB in human plasma by LC-MS/MS for routine sample analysis. Also, the sensitivity of the method should be adequate to monitor at least five half lives of CXB concentration with good accuracy and precision for subject sample analysis. During method development, electro spray ionization of CXB and CXB-D7 (IS) was conducted in negative ionization mode as both are basic in nature due to presence of tertiary and secondary amine groups, using $10.0 \mathrm{ng} / \mathrm{ml}$ tuning solution. The analyte and IS gave predominant singly charged 
deprotonated precursor $[\mathrm{M}-\mathrm{H}]$-ions at $\mathrm{m} / \mathrm{z}$ of 380.0 and 387.0 for CXB and IS, respectively in Q1 full scan spectra as reported previously [10]. Further, fragmentation was initiated using sufficient nitrogen for CAD and by applying 25.0 psi curtain gas to break the precursor ions. The most abundant and consistent ion found in the product ions in Q3 mass spectra of CXB and IS were at $m / z 315.9$ and 323.0, respectively. These ions were formed from the deprotonated parent ion by removal of sulfur dioxide (fig. 1a and 1b). To attain an ideal Taylor cone for better spectral response, nebulizer gas pressure was set at 55 psi. Fine tuning of nebulizer gas and CAD gas was done to get a consistent and stable response. Ion spray voltage and temperature did not have any significant impact on analyte response and hence were maintained at- $4500 \mathrm{~V}$ and 500 ${ }^{\circ} \mathrm{C}$ respectively. A dwell time of $500 \mathrm{~ms}$ was found adequate for CXB and IS. Also, no cross talk was observed between the MRMs of analyte and IS. (a)

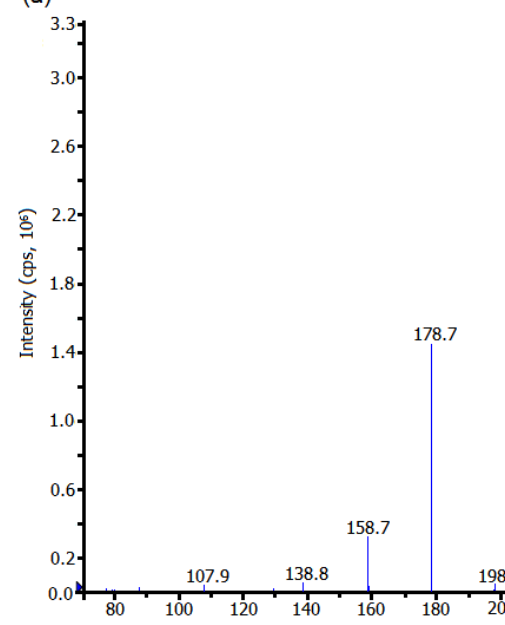

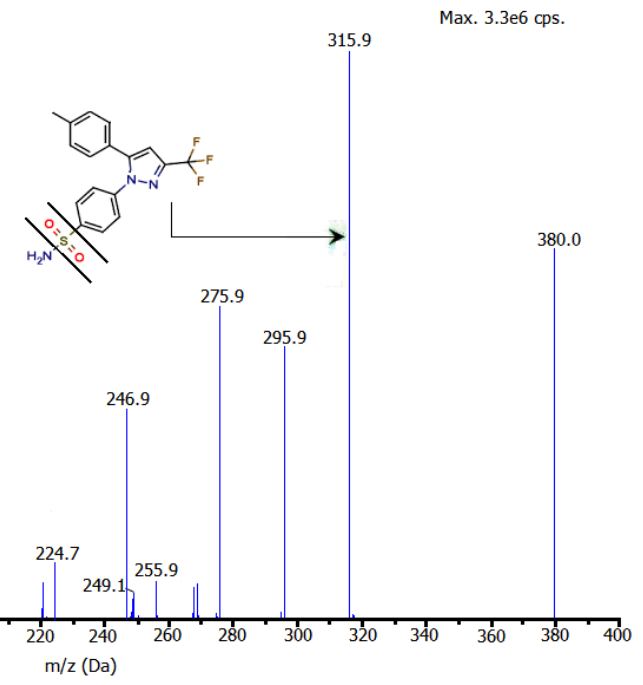

Max. $2.7 \mathrm{e} 6 \mathrm{cps}$

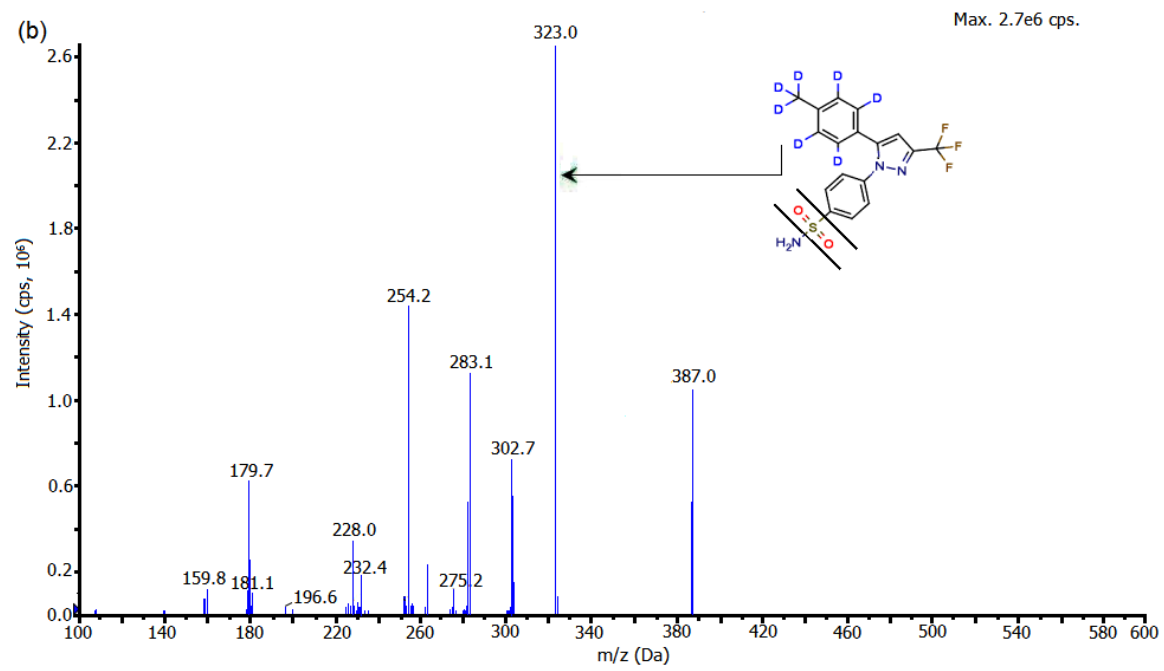

Fig. 1: Product ion mass spectra of (a) celecoxib $(m / z$ 380.0 $\rightarrow 315.9$, scan range 70-400 Da) and (b) celecoxib-D7 (IS, $m / z$ 387.0 $\rightarrow 323.0$, scan range 100-600 Da) in the negative ionization mode

The chromatographic conditions were set to obtain adequate retention and response with minimal interference from the endogenous components. This included optimization of mobile phase, its composition, flow rate, column type, dilution preparation medium and injection volume. Different combinations of acetonitrile/methanol and acidic buffers (ammonium formate/ formic acid, ammonium acetate/acetic acid) of different strengths (2.0-5.0 mmol) were tested as mobile phase. Further, mobile phase additives like formic acid and ammonium trifluoroacetate were also tried on Hypurity C18 $(100 \times 4.6 \mathrm{~mm}, 5 \mu \mathrm{m})$, ACE C18-300 (100 $\times$ $4.6 \mathrm{~mm}, 5 \mu \mathrm{m})$, Eclipse XDB-C8 $(150 \times 4.6 \mathrm{~mm}, 3.5 \mu \mathrm{m})$, Hypurity C8 $(100 \times 4.6 \mathrm{~mm}, 5 \mu \mathrm{m})$, ACE C8-300 $(50 \times 4.0 \mathrm{~mm}, 3 \mu \mathrm{m})$ and Kinetex XB C18, $100 \AA(50 \times 4.6 \mathrm{~mm}, 2.5 \mu \mathrm{m})$ columns. In addition, the effect of flow rate was also studied from 0.5 to $1.2 \mathrm{ml} / \mathrm{min}$, which was responsible for acceptable chromatographic peak shapes and to separate endogenous peaks. All the columns provided acceptable separation of the analyte from endogenous substances within 5.0 min but the analyte response at the QC levels was much superior on ACE C8-300 compared to other columns. Further, it required a run time of $2.5 \mathrm{~min}$ for the analysis of CXB and IS on this column using methanol-1.0 mmol ammonium acetate in 80:20 (v/v) ratio as the mobile phase. The analysis time was much less compared to previous reports $[8,10,11]$, which required more than $5.0 \mathrm{~min}$. Addition of $1.0 \mathrm{mmol}$ ammonium acetate was sufficient to get adequate response and also good peak shape for CXB. A flow rate of $0.5 \mathrm{ml} / \mathrm{min}$ ensured retention time of 1.44 and $1.43 \mathrm{~min}$ for CXB and IS, respectively (fig. 2). The reproducibility in the measurement of retention times for $\mathrm{CXB}$ was $\leq 0.8 \%$ ( $\% \mathrm{CV}$ ) for 100 injections on the same column. Further, there was no effect of IS on analyte recovery, sensitivity or ion suppression. In the present work, PP was tried initially with methanol and acetonitrile; however, the samples obtained were not clear in either of the solvents with poor recovery and considerable ion suppression. LLE was also initiated with different solvents like diethyl ether, $n$-hexane, dichloromethane, 
methyl tert-butyl ether (MTBE) and ethyl acetate, alone and in combination under alkaline conditions. The results obtained in MTBE were encouraging, but the recovery was not consistent at lower QC levels. Moreover, in one report the recovery of CXB obtained was about $45 \%$ using MTBE as the extraction solvent [12]. Hence, SPE was tested with Strata- $X^{\circledR}$ under acidic, neutral and basic conditions. Precise and quantitative recoveries (83.4$90.2 \%$ ) with minimum matrix interference were obtained under acidic conditions during application of the sample on the cartridges. While neutral conditions (methanol-1.0 mmol ammonium acetate $(80: 20, v / v)$ for elution was optimal for the analyte and IS.
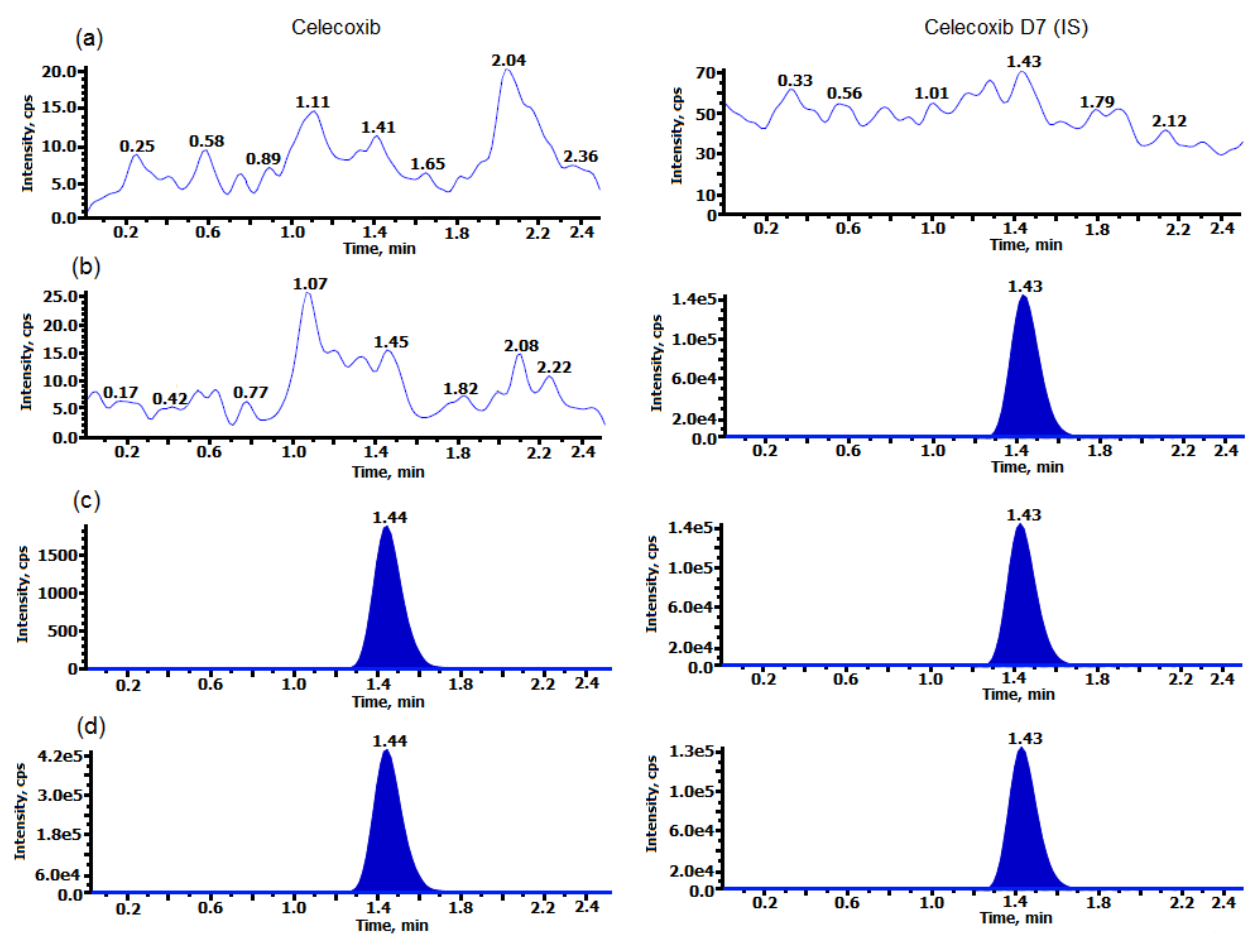

Fig. 2: MRM ion-chromatograms of celecoxib $(\mathrm{m} / \mathrm{z} 380.0 \rightarrow 315.9)$ and celecoxib $\mathrm{D} 7(\mathrm{IS}, \mathrm{m} / \mathrm{z} 387.0 \rightarrow 323.0)$ in (a) double blank plasma (without analyte and IS), (b) blank plasma with IS, (c) celecoxib at LLOQ and IS (d) real subject sample at $C_{\text {max }}$ after administration of 400 mg dose of celecoxib under fasting condition

\section{Assay performance and validation}

It is indispensable to apply well-characterized and fully validated bioanalytical methods to obtain reliable and consistent results for routine analysis [18]. The developed bioanalytical method was fully validated for all validation parameters as explained below.

Selectivity, carry over and interference study: The purpose of evaluating selectivity with 12 different human plasma sources was to determine the extent to which endogenous plasma components might interference at the retention time of CXB and the IS and thus, ensure the authenticity of the results for study sample analysis. Fig. 2 demonstrates the selectivity of the method through the chromatograms of double blank plasma, blank plasma spiked with IS, CXB at LLOQ concentration respectively and in subject samples. Carry-over evaluation was performed in each analytical run to ensure that it does not impact the accuracy and precision of the method. The experiments showed a carryover of $\leq 1.07 \%$ for CXB of LLOQ concentration in blank plasma sample after injection of highest calibration standard (ULOQ) at the retention time of analyte and IS. Further, there was no interference of commonly used medications by healthy volunteers like acetaminophen, aspirin, caffeine, chlorpheniramine, cetrizine, ibuprofen and pseudoephedrine at the retention time of analyte and IS.

Linearity, sensitivity, accuracy and precision: The calibration curve were linear over the concentration range of $10.0-4000 \mathrm{ng} / \mathrm{ml}$ with correlation coefficient $r^{2} \geq 0.9987$ as shown in fig. 3. A straight-line fit was made through the data points by least square regression analysis to give the mean linear equation $y=(0.0012) x-(0.0001)$, where $y$ is the peak area ratio of the analyte/IS and $x$ the concentration of the analyte. The accuracy and precision (\% CV) observed for the CSs ranged from 95.0 to $106 \%$ and 1.6 to $5.7 \%$, respectively. The lowest concentration (LLOQ) in the standard curve that can be measured with acceptable accuracy and precision found was $10.0 \mathrm{ng} / \mathrm{ml}$ at a signal-to-noise ratio $(\mathrm{S} / \mathrm{N}) \geq 25$, with a limit of detection (LOD) of $2.5 \mathrm{ng} / \mathrm{ml}$. The intra-batch and inter-batch precision and accuracy results are summarized in table 1 . The intrabatch precision $(\% \mathrm{CV})$ ranged from 0.7 to 5.7 and the accuracy was within 90.2 to $104 \%$. For the inter-batch experiments, the precision varied from 1.8 to 7.2 and the accuracy was within 88.4 to $98.8 \%$.

Recovery, matrix effect and post-column analyte infusion study: The extraction recovery and matrix effect data for the analyte and IS is presented in table 2 . Highly consistent recovery was obtained across QC levels for CXB. The IS-normalized matrix factors ranged from 0.99-1.03, which shows minimal interference of endogenous matrix components for CXB. Matrix effect in different plasma sources (6$\mathrm{K}_{2}$ EDTA, 1-lipemic and 1-heamolyzed) was also evaluated at LQC and HQC levels. The precision values in different plasma sources varied from 0.5 to $2.9 \%$ for CXB (table 3). Further, results of postcolumn analyte infusion experiment showed no regions of ion suppression or enhancement at the retention time of analyte and IS.

Stability, dilution integrity and ruggedness study: Stability experiments were performed to evaluate the analyte stability in stocks solutions and in plasma samples under different conditions, simulating the same conditions which occurred during study sample analysis. CXB was found stable in controlled blank plasma at room temperature up to $25 \mathrm{~h}$ and for six freeze and thaw cycles. The analyte in extracted plasma samples was stable for $117 \mathrm{~h}$ under refrigerated conditions $\left(2-8{ }^{\circ} \mathrm{C}\right)$ and for $69 \mathrm{~h}$ at room temperature. The spiked plasma samples of CXB stored at $-20^{\circ} \mathrm{C}$ and $-70^{\circ} \mathrm{C}$ for long term stability showed no evidence of degradation up to $126 \mathrm{~d}$. The detailed stability results are shown in table 4 . 


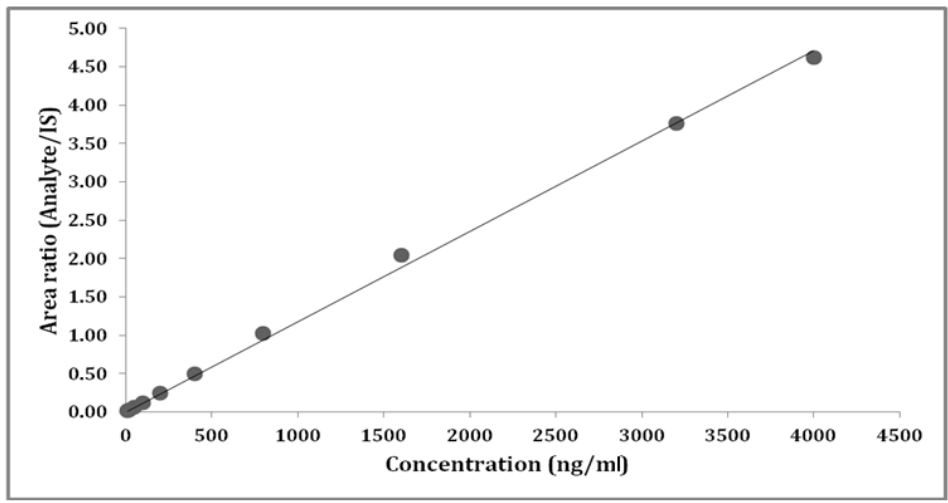

Fig. 3: Linear calibration curve for celecoxib in plasma

Table 1: Intra-batch and inter-batch accuracy and precision results for celecoxib

\begin{tabular}{|c|c|c|c|c|c|c|}
\hline \multirow{2}{*}{$\begin{array}{l}\text { Analytes and } \\
\text { QC level (ng/ml) }\end{array}$} & \multicolumn{3}{|c|}{ Intra-day ( $n=6$; single batch) } & \multicolumn{3}{|c|}{ Inter-day ( $n=18 ; 6$ from each batch) } \\
\hline & $\begin{array}{l}\text { Mean conc. found } \\
(\mathrm{ng} / \mathrm{ml})\end{array}$ & $\begin{array}{l}\text { Accuracy } \\
(\%)\end{array}$ & $\begin{array}{l}\text { Precision } \\
(\% \mathrm{CV})\end{array}$ & $\begin{array}{l}\text { Mean conc. found } \\
(\mathrm{ng} / \mathrm{ml})\end{array}$ & $\begin{array}{l}\text { Accuracy } \\
(\%)\end{array}$ & $\begin{array}{l}\text { Precision } \\
(\% \mathrm{CV})\end{array}$ \\
\hline LLOQ (10.00) & 9.02 & 90.2 & 3.3 & 8.84 & 88.4 & 7.2 \\
\hline LQC $(30.00)$ & 31.21 & 104 & 5.7 & 29.65 & 98.8 & 4.6 \\
\hline MQC-2 (300.0) & 278.5 & 92.8 & 1.6 & 274.2 & 91.4 & 2.2 \\
\hline MQC-1 (1200) & 1106 & 92.2 & 0.7 & 1097 & 91.4 & 2.5 \\
\hline $\mathrm{HQC}(3000)$ & 2801 & 93.4 & 0.9 & 2763 & 92.1 & 1.8 \\
\hline ULOQ (4000) & 3623 & 90.6 & 0.7 & 3554 & 88.9 & 1.8 \\
\hline
\end{tabular}

LQC: low quality control; MQC: medium quality control; HQC: high quality control, LLOQ QC: lower limit of quantitation quality control; CV: coefficient of variation

Table 2: Extraction recovery and matrix factor for celecoxib $(n=6)$

\begin{tabular}{|c|c|c|c|c|c|c|c|c|}
\hline \multirow{2}{*}{$\begin{array}{l}\text { Quality control } \\
\text { level } \\
(\mathrm{ng} / \mathrm{ml})\end{array}$} & \multicolumn{3}{|c|}{ Mean area response $(n=6)$} & \multicolumn{2}{|c|}{ Recovery (B/A \%) } & \multicolumn{3}{|c|}{ Matrix factor } \\
\hline & $\begin{array}{l}\text { A (post-extraction } \\
\text { spiking) }\end{array}$ & $\begin{array}{l}\text { B (pre-extraction } \\
\text { spiking) }\end{array}$ & $\begin{array}{l}\text { C (neat samples } \\
\text { in mobile phase) }\end{array}$ & CXB & IS & $\begin{array}{l}\text { CXB } \\
(A / C)\end{array}$ & IS & $\begin{array}{l}\text { IS-normalized } \\
\text { (CXB/IS) }\end{array}$ \\
\hline 30.00 & 46265 & 41735 & 47734 & 90.2 & 85.1 & 0.97 & 0.94 & 1.03 \\
\hline 300.0 & 448323 & 377718 & 476773 & 84.3 & 84.0 & 0.94 & 0.95 & 0.99 \\
\hline 1200 & 1774993 & 1480750 & 1882271 & 83.4 & 85.3 & 0.94 & 0.93 & 1.01 \\
\hline 3000 & 4173424 & 3514982 & 4614796 & 84.2 & 84.7 & 0.90 & 0.88 & 1.02 \\
\hline
\end{tabular}

IS: internal standard, Celecoxib-D7

Table 3: Relative matrix effect in different lots of human plasma for celecoxib $(n=4)$

\begin{tabular}{|c|c|c|}
\hline \multirow[t]{2}{*}{ Plasma lots } & \multicolumn{2}{|c|}{ Mean calculated concentration (\% CV) } \\
\hline & $30.00 \mathrm{ng} / \mathrm{ml}$ & $3000 \mathrm{ng} / \mathrm{ml}$ \\
\hline Lot-1 (K $\mathrm{K}_{2}$ EDTA) & $31.26(1.1)$ & $3198(1.8)$ \\
\hline Lot-2 (K $\mathrm{K}_{2}$ EDTA) & $31.41(0.5)$ & 3197 (1.8) \\
\hline Lot-3 (K2 EDTA) & $31.04(1.7)$ & $3187(2.2)$ \\
\hline Lot-4 (K2 EDTA) & $31.25(1.8)$ & $3189(1.6)$ \\
\hline Lot-5 (K $\mathrm{K}_{2}$ EDTA) & $31.29(0.5)$ & $3185(2.5)$ \\
\hline Lot-6 (K $\mathrm{K}_{2}$ EDTA) & $31.23(0.7)$ & 3181 (2.9) \\
\hline Lot-7 (haemolysed) & $31.64(0.6)$ & $3185(2.0)$ \\
\hline Lot-8 (lipemic) & $31.04(0.9)$ & $3182(1.5)$ \\
\hline
\end{tabular}

Table 4: Stability results for celecoxib under different conditions $(n=6)$

\begin{tabular}{|c|c|c|c|c|}
\hline Storage Condition & QC level & Mean stability sample (ng/ml) & CV (\%) & Change (\%) \\
\hline Bench top stability & LQC & 28.32 & 1.2 & -5.6 \\
\hline$\left(25 \mathrm{~h}, 25^{\circ} \mathrm{C}\right)$ & HQC & 2818 & 2.7 & -6.1 \\
\hline Freeze-thaw stability & LQC & 29.63 & 1.2 & -1.2 \\
\hline$\left(6\right.$ cycles,$\left.-20^{\circ} \mathrm{C}\right)$ & HQC & 2892 & 0.9 & -3.6 \\
\hline Auto sampler stability & LQC & 27.77 & 2.0 & -7.4 \\
\hline$\left(117 \mathrm{~h}, 2-8^{\circ} \mathrm{C}\right)$ & HQC & 2698 & 1.2 & -10.1 \\
\hline Processed sample stability & LQC & 29.56 & 1.4 & -1.5 \\
\hline$\left(69 \mathrm{~h}, 25^{\circ} \mathrm{C}\right)$ & HQC & 2824 & 1.3 & -5.9 \\
\hline Long term stability & LQC & 31.22 & 1.1 & 4.1 \\
\hline$\left(126 \mathrm{~d},-20^{\circ} \mathrm{C}\right)$ & HQC & 2893 & 1.7 & -3.6 \\
\hline Long term stability & LQC & 31.30 & 2.1 & 4.3 \\
\hline$\left(126 \mathrm{~d},-70^{\circ} \mathrm{C}\right)$ & HQC & 2836 & 5.0 & -5.5 \\
\hline
\end{tabular}

LQC: low quality control; HQC: high quality control; CV: coefficient of variation 
$\%$ Change $=\frac{\text { Mean stability samples }- \text { Mean comparison samples }}{\text { Mean comparison samples }} \times 100$

Dilution integrity: The dilution reliability of the method was checked to confirm dilution reliability of samples having concentration above ULOQ. The precision (\% CV) value for 10-fold dilution (20000 $\mathrm{ng} / \mathrm{ml}$ ) of CXB was $1.3 \%$ and the corresponding accuracy was 97.3 $\%$. The results obtained were well within the acceptance limit of 15 $\%$ for precision (\%CV) and 85 to $115 \%$ for accuracy. Similarly, the precision and accuracy for method ruggedness performed on two different ACE C8-300 columns and with different analysts varied from 1.0 to $3.0 \%$ and 95.8 to $107 \%$, respectively for CXB

\section{Application of the method in healthy subjects}

The validated method was applied to a bioequivalence study of CXB under fasting and fed states in 50 and 42 healthy Indian subjects, respectively after oral administration of $400 \mathrm{mg}$ test and reference formulations of CXB. The study was performed to evaluate the impact of food on the pharmacokinetics of CXB. The method was sensitive enough to monitor their plasma concentration up to $72 \mathrm{~h}$. Fig. 4 shows the plasma concentration vs. time profile of CXB in healthy subjects under fasting and fed conditions. Table 5 gives a comparative assessment of pharmacokinetic parameters obtained for the study. The equivalence statistics of bioavailability for the pharmacokinetic parameters of the two formulations are summarized in table 6. No statistically significant differences were found between the two formulations in any parameter. Further, there was no clinically relevant effect of food on the pharmacokinetics of CXB. Approximately 4641 samples including the calibration, QC and volunteer samples were run and analyzed successfully. The \% change in the measurement of selected subject samples for ISR was within $\pm 20 \%$ which confirms method reproducibility. Further, there was no adverse event during the course of the study. (a)

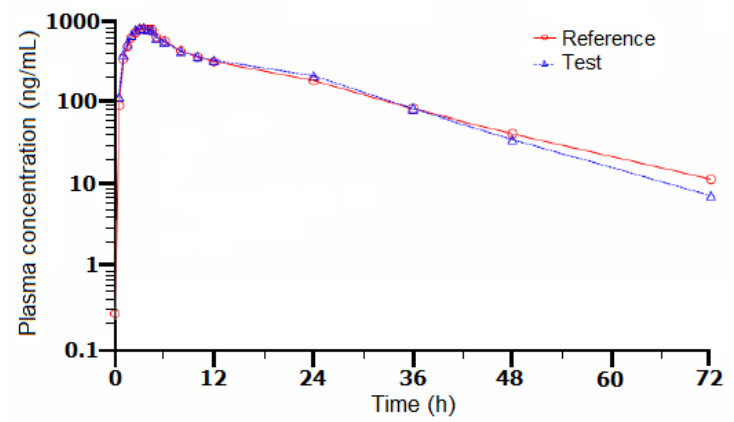

(b)

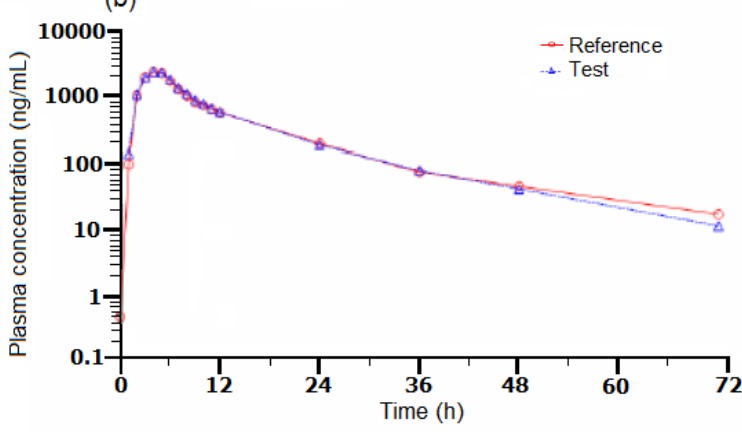

Fig. 3: Mean plasma concentration-time profile of celecoxib after oral administration of $400 \mathrm{mg}$ capsules (test and reference) formulation to 50 and 42 healthy Indian subjects under (a) fasting and (b) fed conditions, respectively

Table 5: Mean pharmacokinetic parameters $( \pm$ SD) following of $400 \mathrm{mg}$ celecoxib capsule formulation to healthy Indian subjects under different condition

\begin{tabular}{lllll}
\hline Parameter & Fasting & & Fed & Reference \\
\cline { 2 - 5 } & Test & Reference & Test & $2525.8 \pm 259.8$ \\
\hline$C_{\max }(\mathrm{ng} / \mathrm{ml})$ & $1834.0 \pm 350.6$ & $2618.0 \pm 330.6$ & $2597.9 \pm 264.9$ & $5.00 \pm 1.00$ \\
$T_{\max }(\mathrm{h})$ & $4.50 \pm 1.00$ & $5.00 \pm 1.00$ & $4.00 \pm 1.00$ & $12.03 \pm 3.52$ \\
$t_{1 / 2}(\mathrm{~h})$ & $25.07 \pm 5.66$ & $26.81 \pm 5.65$ & $11.87 \pm 2.68$ & $18613.8 \pm 1578.2$ \\
AUC $_{0-72 h}(\mathrm{~h} . \mathrm{ng} / \mathrm{ml})$ & $63798.3 \pm 3962.6$ & $77354.5 \pm 4290.7$ & $19191.1 \pm 1298.9$ & $19037.8 \pm 1206.4$ \\
AUC $_{0-\text { inf }}(\mathrm{h} . \mathrm{ng} / \mathrm{ml})$ & $75374.0 \pm 4271.6$ & $94862.1 \pm 4417.1$ & $19563.3 \pm 1543.9$ & $0.0707 \pm 0.015$ \\
$K_{\text {el }}(1 / \mathrm{h})$ & $0.123 \pm 0.028$ & $0.123 \pm 0.026$ & $0.0703 \pm 0.016$ & \\
\hline
\end{tabular}

$C_{\max }$ : maximum plasma concentration; $T_{\max }$ : time point of maximum plasma concentration, $t_{1 / 2}$ : half-life of drug elimination during the terminal phase; $A_{0-t}$ : area under the plasma, concentration-time curve from zero hour to $72 \mathrm{~h}$; $\mathrm{AUC}_{0 \text {-inf: }}$ area under the plasma concentration-time curve from zero hour to infinity; $\mathrm{K}_{\mathrm{el}}$ : elimination rate constant; SD: standard deviation.

Table 6: Comparison of treatment ratios and $90 \%$ CIs of natural log (Ln)-transformed parameters for 400 mg celecoxib capsule test and reference formulations under fasting and fed states

\begin{tabular}{|c|c|c|c|c|c|c|c|c|}
\hline \multirow[t]{2}{*}{ Parameter } & \multicolumn{2}{|c|}{$\begin{array}{l}\text { Ratio (test/ } \\
\text { reference), } \%\end{array}$} & \multicolumn{2}{|c|}{$\begin{array}{l}90 \% \text { confidence interval } \\
\text { (Lower-upper) }\end{array}$} & \multicolumn{2}{|l|}{ Power } & \multicolumn{2}{|c|}{ Intra subject variation, CV (\%) } \\
\hline & Fast & Fed & Fast & Fed & Fast & Fed & Fast & Fed \\
\hline$C_{\max }(\mathrm{ng} / \mathrm{ml})$ & 105.2 & 102.9 & $97.2-113.8$ & $98.18-107.7$ & 0.9982 & 1.0000 & 23.86 & 12.51 \\
\hline $\mathrm{AUC}_{0-72 \mathrm{~h}}(\mathrm{~h} . \mathrm{ng} / \mathrm{ml})$ & 104.5 & 103.1 & $99.0-110.3$ & $99.34-107.0$ & 1.0000 & 1.0000 & 16.11 & 9.99 \\
\hline $\mathrm{AUC}_{0-\inf }(\mathrm{h} . \mathrm{ng} / \mathrm{ml})$ & 103.9 & 102.8 & $98.3-109.8$ & $98.93-106.7$ & 1.0000 & 1.0000 & 16.61 & 10.21 \\
\hline
\end{tabular}

$\mathrm{CV}$ : coefficient of variation

\section{CONCLUSION}

The present study describes a new, highly selective and rugged LCMS/MS method for the estimation of CXB in human plasma, especially to meet the requirement for subject sample analysis. The SPE employed in the present work using Strata X cartridges gave consistent and reproducible recoveries for CXB. The optimized linear concentration range was adequate to monitor at least five half-lives of CXB with good accuracy and precision. Finally, the reproducibility of the method was adequately proved through incurred sample reanalysis of subject samples for the first time.

\section{ACKNOWLEDGEMENT}

The authors are indebted to Mr. Vijay Patel, Executive Director, Cliantha Research Ltd., Ahmedabad for providing necessary facilities to carry out this work and to Mr. Anshul Dogra, Head of the Department, Cliantha Research Ltd. for his support during the course of this project.

\section{AUTHORS CONTRIBUTIONS}

Nirav P. Patel performed the experimental work and data collection. Mallika Sanyal, Pranav S. Shrivastav and Bhavin N. Patel were 
equally responsible for the design of the work and writing the manuscript.

\section{CONFLICT OF INTERESTS}

There are no conflicts of interest to declare

\section{REFERENCES}

1. Frampton JE, Keating GM. Celecoxib: a review of its use in the management of arthritis and acute pain. Drugs 2007;67:2433-72.

2. Davies NM, McLachlan AJ, Day RO, Williams KM. Clinical pharmacokinetics and pharmacodynamics of celecoxib: a selective cyclo-oxygenase-2 inhibitor. Clin Pharmacokinet 2000;38:225-42.

3. Chow HHS, Anavy N, Salazar D, Frank DH, Alberts DS. Determination of celecoxib in human plasma using solid-phase extraction and high-performance liquid chromatography. J Pharm Biomed Anal 2004;34:167-74.

4. Jalalizadeh H, Amini M, Ziaee V, Safa A, Farsam H, Shafiee A. Determination of celecoxib in human plasma by highperformance liquid chromatography. J Pharm Biomed Anal 2004;35:665-70.

5. Emami J, Fallah R, Ajami A. A rapid and sensitive HPLC method for the analysis of celecoxib in human plasma: application to the pharmacokinetic studies. DARU 2008;16:211-7.

6. Zarghi A, Shafaati A, Foroutan SM, Khoddam A. Simple and rapid high-performance liquid chromatographic method for determination of celecoxib in plasma using UV detection: application in pharmacokinetic studies. J Chromatogr B 2006;835:100-4.

7. Zhang M, Moore GA, Gardiner SJ, Begg EJ. Determination of celecoxib in human plasma and breast milk by highperformance liquid chromatographic assay. J Chromatogr B 2006;830:245-8.

8. Abdel-Hamid M, Novotny L, Hamza H. Liquid chromatographicmass spectrometric determination of celecoxib in plasma using single-ion monitoring and its use in clinical pharmacokinetics. J Chromatogr B 2001;753:401-8.

9. Gika HG, Theodoridou A, Michopoulos F, Theodoridis G, Diza E, Settas L, et al. Determination of two COX-2 inhibitors in serum and synovial fluid of patients with inflammatory arthritis by ultra performance liquid chromatography-inductively coupled plasma mass spectroscopy and quadrupole time-of-flight mass spectrometry. J Pharm Biomed Anal 2009;49:579-86.

10. Brautigam L, Vetter G, Tegeder I, Heinkele G, Geisslinger G. Determination of celecoxib in human plasma and rat microdialysis samples by liquid chromatography tandem mass spectrometry. J Chromatogr B 2001;761:203-12.

11. Werner U, Werner D, Pahl A, Mundkowski R, Gillich M, Brune K. Investigation of the pharmacokinetics of celecoxib by liquid chromatography-mass spectrometry. Biomed Chromatogr 2002;16:56-60.

12. Park MS, Shim WS, Yim SV, Lee KT. Development of simple and rapid LC-MS/MS method for determination of celecoxib in human plasma and its application to bioequivalence study. J Chromatogr B 2012;902:137-41.

13. Guidance for Industry, Bioanalytical Method Validation, US Department of Health and Human Services, Food and Drug Administration Centre for Drug Evaluation and Research (CDER), Centre for Veterinary Medicine (CVM); 2001.

14. Patel DS, Sharma N, Patel MC, Patel BN, Shrivastav PS, Sanyal M. Development and validation of a selective and sensitive LC-MS/MS method for determination of cycloserine in human plasma: application to bioequivalence study. J Chromatogr B 2011;879:2265-73.

15. Logoyda L. Bioanalytical method development and validation for the simultaneous determination of verapamil and enalapril in the present of enalaprilat by HPLC-MS/MS. Int J Appl Pharm 2018;10:9-27.

16. Guidance for Industry: ICH E6 Good Clinical Practice, U. S. Department of Health and Human Services, Food and Drug Administration, Centre for Drug Evaluation and Research (CDER), Centre for Biologics Evaluation and Research (CBER); 1996.

17. Yadav M, Shrivastav PS. Incurred sample reanalysis: a decisive tool in bioanalytical research. Bioanalysis 2011;3:1007-24.

18. Tijare LK, Rangari NT, Mahajan UN. A review on bioanalytical method development and validation. Asian J Pharm Clin Res 2016;9 Suppl 3:6-10. 